\title{
O Brasil no limiar do terceiro milênio
}

\section{PAUL SINGER}

\section{Desafios}

$\mathrm{O}$ BRASIL CARREGa a sina dos países atrasados, que constituem (pelo menos desde o início da globalização, no século XV) a grande maioria. Com o capitalismo industrial, a partir do fim do século XVIII, criou-se uma divisão internacional de trabalho que partiu o mundo, por quase dois séculos, entre um grupo de nações - o chamado núcleo orgânico - de exportadoras de produtos manufaturados e de capitais e outro - periféricoconstituído pelas demais, exportadoras de produtos primários. O núcleo orgânico da economia mundial monopolizava o progresso técnico e, por isso, era adiantado: tinha produtividade sempre mais elevada, ditava os padrões de consumo nos países semiperiféricos e periféricos, transmitia suas teorias científicas e ideologias políticas aos mesmos.

Obviamente, para os países excluídos do núcleo orgânico, o grande desafio era e continua sendo superar o atraso mediante desenvolvimento acelerado, transformando-se de país importador de capitais, tecnologia, modas e idéias em produtor e exportador dos mesmos. Cumpre notar que, a partir do final do século XIX, um crescente número de países conseguiu vencer este desafio: os Estados Unidos e a Alemanha primeiro, mas quase em seguida vários países da Europa ocidental e central, além de Canadá, Austrália e Nova Zelândia. Após esta primeira leva, uma segunda conseguiu superar o atraso na última metade do século XX, na qual se destacam Japão, Itália e Espanha e que inclui países asiáticos como Coréia do Sul, Taiwan e Singapura.

É interessante observar que, nos últimos 50 anos, o número de países que começou a se desenvolver foi muito maior do que o dos que lograram superar inteiramente o atraso. A maioria das chamadas economias em desenvolvimento ficou no meio do caminho. Alcançou níveis expressivos de industrialização e urbanização, formou uma burguesia nacional e uma classe média de assalariados com renda relativamente elevada, mas nas últimas duas décadas seu ritmo de desenvolvimento arrefeceu e a distância entre eles e o núcleo orgânico voltou a aumentar. São os países semidesenvolvidos, 
nos quais uma parte importante da população permanece mergulhada na pobreza e no atraso.

A América Latina, liderada de certa maneira por Brasil, México e Argentina, seguiu esse percurso. Tendo sido descolonizada muito antes da Ásia e da África, a América Latina pôde iniciar seu desenvolvimento por substituição de importações antes da Primeira Guerra Mundial e já integrava a semiperiferia em meados do século XIX. Não por acaso, a mais sofisticada teoria do desenvolvimento, a da dependência, é em sua origem latinoamericana. Quando a teoria foi formulada, na CEPAL, o desafio de vencer o atraso estava bem consciente no Brasil e nos países vizinhos. E até 1980, tudo levava a crer que pelo menos o Brasil (e possivelmente o México) estava em vias de lográ-lo.

Mas, a partir de 1980, a economia mundial começou a entrar em uma série de crises, sinalizando profundas transformações em seus fundamentos. A maior de todas foi a desregulamentação, na verdade a privatização, do mercado mundial de capitais, decisiva para que, a partir desta época, a hegemonia na economia mundial passasse das mãos dos governos nacionais articulados a empresas produtivas para as de multiempresas internacionais, capitaneadas pelo que se pode chamar de capital financeiro.

Não cabe, nos limites deste breve ensaio, discutir a etimologia de capital financeiro. Importa esclarecer que ele se refere ao capital dos intermediários financeiros (também chamado capital bancário), ou seja, trata-se duma fração do capital especializado na prestação de serviços financeiros: emissão de meios de pagamento, guarda e administração de valores, concessão de financiamentos, emissão de contratos de seguros etc. O capital financeiro é o principal arquiteto da acumulação de capital realizada pelos capitais produtivos, isto é, investidos em atividades produtoras de valores de uso (bens e serviços que satisfazem direta ou indiretamente necessidades finais). O capital financeiro representa os interesses - e em geral compartilha a visão de mundo - dos detentores de riqueza financeira, ou seja, do capital aplicado em ativos financeiros: depósitos bancários, ações, fundos de pensão, fundos de investimento, títulos de dívida pública ou privada etc.

Os detentores de ativos financeiros não constituem uma classe, pois a maior parte da população está nesta categoria, inclusive todos os beneficiários da previdência social e do FGTS, no Brasil. Mas, há um pequeno número de grandes detentores de ativos financeiros que exerce profissionalmente a especulação financeira, contribuindo para reconfigurar a economia mundial periodicamente mediante a movimentação de fluxos de capital. Este grupo, que podemos chamar de burguesia rentista, até a década de 70 teve de se 
submeter, conjuntamente com o capital financeiro, às diretrizes das autoridades monetárias nacionais e aos planos nacionais de desenvolvimento, liderados freqüentemente pelas empresas de serviços de infra-estrutura, inseridas em sua maioria no setor produtivo estatal. A partir de então, a burguesia rentista passou a gozar cada vez de mais liberdade para movimentar seus capitais entre países e setores, e assim adquiriu uma arma fatal - a fuga de capitais - para punir os governos que contrariassem seus interesses e/ou ideais.

O interesse primordial da burguesia rentista está em apreciar o seu capital e evitar que ele seja depreciado por inflação. Como todos sabem, a inflação transfere renda dos credores aos devedores, pois a subida dos preços diminui o poder aquisitivo dos créditos. Por definição, todos os rentistas são credores. Para a burguesia rentista, um governo que promove inflação é um inimigo mortal e governos que a toleram ou são incompetentes em combatê-la devem ser substituídos. Além disso, é de interesse da burguesia rentista que a taxa de juros seja alta, ao menos mais alta do que a inflação esperada, o que contraria o interesse dos investidores de capital produtivo, pois estes financiam suas inversões a juros e se obrigam a pagá-los a partir de seus lucros.

A incompatibilidade entre o interesse do rentista e a manutenção do pleno emprego foi, há mais de 60 anos, reconhecida por Keynes: “ ... a poupança efetiva é determinada necessariamente pela escala da inversão e a escala de inversão é promovida por uma baixa taxa de lucro ... Assim, é para a nossa melhor vantagem reduzir a taxa de juros ... é provável que a taxa de juros caia perenemente, se é para tornar viável manter condições mais ou menos contínuas de pleno emprego ... o retorno deles [dos instrumentos de capital] teria de cobrir pouco mais do que seu desgaste pelo uso e obsolescência junto com alguma margem para cobrir risco e o exercício de habilidade e julgamento. (...) Bem, embora esta situação seja bastante compatível com individualismo em certa medida, ela significaria a eutanásia do rentista e conseqüentemente a eutanásia do poder opressor cumulativo do capitalista em explorar o valor de escassez do capital" (Keynes, 1936:375376 , sublinhado no original)

Infelizmente, a previsão de Keynes de que a manutenção do pleno emprego acabaria provocando a eutanásia do rentista não se verificou. Durante cerca de 30 anos, os países do núcleo orgânico se mantiveram próximos do pleno emprego, subordinando os rentistas a políticas nacionais de desenvolvimento. Mas, a rebeldia de estudantes e jovens operários em maio de 1968 e os choques do petróleo dos anos 70 provocaram elevada inflação 
nos países adiantados, o que desmoralizou a política de desenvolvimento e de pleno emprego e ensejou a reviravolta neoliberal. O essencial da mudança fundamental acima referida foi realizada durante a gestão de Paul Volker (1979-1987) no Fed, o banco central dos EUA.

Volker adotou o monetarismo como doutrina da política monetária e durante quatro anos - de 1979 a 1983 - arrochou o crédito nos Estados Unidos, provocando assim a mais profunda e longa recessão desde os anos 30. Devido ao grande peso da economia norte-americana na economia mundial, os bancos centrais dos outros países foram obrigados a imitar o $\mathrm{Fed}$, de modo que a recessão os atingiu igualmente. A taxa de juros subiu em um nível inédito em tempos de paz, o que impedia países fortemente endividados de servir seus débitos. O debacle da moeda mexicana, em agosto de 1982, inaugurou a crise da dívida externa, que atingiu toda a América Latina e os países da Europa Oriental, Ásia e África. O Brasil e outros países que até então estavam superando o atraso foram violentamente arremessados de volta a ele.

A contra-revolução de Volker foi esmiuçada por Greider (1987) em obra destinada a virar clássico, intitulada sugestivamente Segredos do templo. Greider mostra que desde sempre as finanças estiveram envolvidas em sacrossanto mistério, como algo importante demais e complexo demais para ser julgado por leigos. Por isso, a opinião pública dos EUA suportou o desemprego, as perdas de salário e os juros de Volker sem se revoltar. O mesmo aconteceu nos outros países. A nova hegemonia financeira alcançou seu desígnio maior: a inflação caiu para não se levantar mais mediante a liquidação do poder de pressão e barganha dos sindicatos operários, dos agricultores e do resto da pequena burguesia. A partir desse período, nos países adiantados, o poder de decisão sobre a economia passou do ministro de economia ou de finanças para o chefe do banco central. Em termos sociais, a hegemonia passou dos administradores públicos, aliados à burguesia industrial e dos serviços, para a burguesia rentista, representada pelos banqueiros, administradores de fundos e operadores do mercado financeiro.

O Brasil demorou um pouco em aderir ao figurino político neoliberal. Em 1990, Collor começou a abrir o mercado interno e provocou imensa recessão inútil para debelar a inflação, mas que serviu para debilitar os setores organizados das classes sociais. Em 1995, FHC acabou com a inflação cavalgando imensa onda de inversões externas, das quais boa parte de curto prazo. Com o real sobrevalorizado, o saldo da balança comercial tornou-se cada vez mais negativo e o déficit da balança de serviços inchou por causa da expansão das remessas de juros, lucros e outros rendimentos, além da 
farra do turismo no exterior. O desenlace já era visível desde 1996, mas os especuladores se deixaram cegar pela incessante demonstração de confiança no governo brasileiro dos ... outros especuladores. É o conhecido comportamento de rebanho: para onde o grosso dos aplicadores vai, os demais são obrigados a ir também.

O Brasil acabou sendo colhido por todas as crises financeiras, pois é o país que mais se endivida e que - depois da China, entre os semiperiféricos mais recebe inversões diretas. Com isso, a década de 90 revelou-se mais perdida que a dos 80. Em termos relativos, o atraso do Brasil aumentou de 1980 para cá. E não apenas em termos quantitativos, ou seja, pelo aumento da diferença de renda per capita entre o Brasil e os países adiantados. O sucateamento de parte da infra-estrutura e a privatização do restante, ao lado da desnacionalização de parcela significativa da grande indústria brasileira também reduzem a possibilidade de o Brasil superar o atraso mediante desenvolvimento acelerado nos próximos anos.

Valores e índices do Produto Nacional Bruto (PNB) per capita em 1960, 1979 e 1995 do G-7, Brasil, Coréia do Sul, Malásia, Federação Russa (URSS) e China

\begin{tabular}{lcccccc}
\hline \multicolumn{1}{c}{ Ano } & \multicolumn{2}{c}{1960} & \multicolumn{2}{c}{1979} & \multicolumn{2}{c}{1995} \\
\hline & US\$ & índice & US\$ & Índice & US\$ & índice \\
\hline G-7 & 6.109 & 100,0 & 8.904 & 100,0 & 25.174 & 100,0 \\
Rússia (1) & 2.750 & 45,0 & 4.110 & 46,2 & 2.240 & 8,9 \\
Brasil & 1.114 & 18,2 & 1.780 & 20,0 & 3.640 & 14,5 \\
Coréia do Sul & 745 & 12,2 & 1.480 & 16,6 & 9.700 & 38,5 \\
Malásia & 925 & 15,1 & 1.370 & 15,4 & 3.890 & 15,5 \\
China & $(2)$ & $(2)$ & 260 & 2,9 & 620 & 2,5 \\
\hline
\end{tabular}

Obs.: (1) URSS em 1960 e 1979; Federação Russa em 1995.

(2) Dados não disponíveis na fonte.

Fonte: Banco Mundial, Relatório sobre o desenvolvimento mundial (diversos anos) 
Na tabela, os dados oferecem uma idéia de como cinco diferentes países, entre os quais o Brasil, aumentaram ou diminuíram o seu atraso em relação aos adiantados, aqui representados pelo G-7, o grupo de países mais ricos do mundo, formado por Japão, Alemanha, Estados Unidos, França, Canadá, Itália e Reino Unido. Adotamos o PNB per capita médio desses sete países como representação da meta que os países atrasados desejam alcançar.

A Rússia, em 1960, já era um país semidesenvolvido, com um PNB per capita de $45 \%$ da meta; 19 anos depois, a então URSS havia se aproximado mais um pouco do G-7, tendo 46,2\% do seu PNB per capita. Neste ritmo, a URSS levaria ainda séculos para se juntar ao núcleo orgânico da economia mundial. Mas, em 1991, no meio de pavorosa crise econômica, a URSS se dissolveu e a maior parte dela formou a atual Federação Russa, que ainda prossegue em regressão econômica. Em 1995, o seu PNB per capita em dólares nominais tinha caído a quase a metade do nível de 1979, representando apenas $8,9 \%$ do G-7.

O Brasil também era semidesenvolvido em 1960, com PNB per capita de $18,2 \%$ da meta; nas duas décadas seguintes, conseguiu acelerar o seu desenvolvimento de modo que em 1979 seu PNB per capita tinha chegado a $20 \%$ do do G-7. Neste ritmo, também o Brasil levaria ainda séculos para se tornar adiantado. E também no nosso caso, o desenvolvimento após 1980 quase cessou, de modo que em 1995 o PNB per capita representava apenas $14,5 \%$ da meta. Em termos relativos, embora o nosso recuo tenha sido minúsculo perto do russo, estávamos em 1995 mais longe da meta (com 14,5\%) do que estivéramos em 1960 (com 18,2\%).

O país que obteve melhor desempenho, dos que constam da tabela, foi a Coréia do Sul. Em 1960, o seu PNB per capita era apenas 12,2\% da meta; em 1979 já alcançava 16,6\% e em 1995 havia encurtado a distância ao chegar a $38,5 \%$ da meta. Tendo somado 21,9 pontos percentuais em 16 anos (1979-1995), a Coréia do Sul alcançaria o PNB per capita do G-7 em mais 45 anos se pudesse continuar a adicionar 1,37 ponto percentual por ano ao seu índice. Não resta dúvida que a Coréia do Sul esteve superando o atraso com um ritmo admirável de desenvolvimento durante os 35 anos abrangidos pela tabela.

A Malásia também se desenvolveu, mas em ritmo apenas um pouco superior ao do núcleo orgânico da economia mundial. Por isso o seu índice apresenta incrementos mínimos, passando de $15,1 \%$ em 1960 para 15,4\% em 1979 e 15,5\% em 1995. Não dá para dizer que a Malásia está superando o seu atraso, mas sua posição em relação à meta em 1995 já era melhor do que a do Brasil. 
O caso da China é o mais intrigante. Em 1979, seu PNB per capita era $2,9 \%$ do da meta, o que pressupõe nível muito baixo de desenvolvimento. A partir desse ano, a sua economia tem crescido a taxas muito elevadas e suas exportações de manufaturados literalmente estouraram no mercado mundial. Não obstante, seu PNB per capita em 1995 representava apenas 2,5\% do da meta, tendo havido regressão relativa. É provável que esse resultado paradoxal seja devido à desvalorização da moeda chinesa, que deve ter ajudado a expandir suas exportações mas reduziu o valor de seu PNB em dólares.

Os dados, embora sumários e baseados numa única variável, não deixam dúvida de que o desafio com que o Brasil se defronta no limiar do terceiro milênio é extremamente difícil, basicamente porque o núcleo orgânico da economia mundial não deixou de crescer também, embora a taxas modestas durante as últimas décadas. Os países adiantados estão desencadeando forte onda de inovação tecnológica, que revoluciona a produtividade do trabalho e os padrões de consumo. Desse modo, os países do núcleo orgânico se adiantam cada vez mais, obrigando as economias que visam vencer seu atraso a acelerar muito o seu desenvolvimento.

Tal aceleração requer um esforço coordenado dos setores público e privado, no sentido de elevar a eficiência dos segmentos já implantados no país e de implantar novos que não só incorporam tecnologias de ponta, mas também satisfazem necessidades básicas do povo. A meta do Brasil não se limita a vencer o atraso, mas que o desenvolvimento beneficie a maioria do povo, até hoje marginalizada da maior parte dos ganhos já logrados.

Vencer o atraso é um desafio colocado pela história, mas ele só adquire sentido concreto se servir para eliminar a pobreza do Brasil, o que exige políticas de geração de trabalho e renda que incorporem o quinto da força de trabalho que está involuntariamente ocioso e o rápido aumento da oferta de bens e serviços que os beneficiários da redistribuição da renda irão querer comprar. Tais políticas significam investir em educação e saúde, habitação e alimentação, em transporte, energia, telecomunicações entre demais serviços de infra-estrutura.

Diante deste desafio, o Brasil enquanto economia política tem se enfraquecido visivelmente. A privatização de serviços de infra-estrutura, precedida por corte de subsídios e conseqüente elevação tarifária, implica menos acesso aos mesmos das camadas de baixa renda. Outro tanto se passa quando bancos públicos, que deveriam servir à clientela de pouca renda, são privatizados e inclusive desnacionalizados. $\mathrm{O}$ ambiente de intensa competição assim criado só beneficia temporariamente os compradores de renda média e alta. E seu resultado será, em pouco tempo, maior concentração 
do capital que reorganize os mercados em forma oligopólica. Este processo já está em pleno curso.

A grande vantagem do Brasil para vencer o atraso tem sido e continua sendo o seu vasto mercado interno. As políticas de liberalização, privatização e desnacionalização negam tal vantagem. $\mathrm{O}$ mercado interno foi aberto às importações, de forma açodada e impensada, permitindo-se o aniquilamento de ramos inteiros de produção e de milhares de empresas nacionais. É claro que tem havido também avanços, em setores modernos e globalizados, como informática e telecomunicações. Só que esses avanços dependem da política econômica das multiempresas globais, que encaram o Brasil como parte integrante de mercados globais, sem qualquer empatia com o desafio de superar o atraso, que infelicita importante parcela do povo.

\section{Dilemas}

Diante deste desafio histórico, o Brasil se defronta com dois dilemas fundamentais. Um, quanto ao modo de se inserir na economia mundial; outro, quanto ao regime de desenvolvimento a adotar.

\section{A inserção na economia mundial}

Como vimos, a economia mundial está sendo crescentemente dominada pelo capital financeiro, o que implica que as agências multilaterais, como o Fundo Monetário Internacional, o Banco Mundial e a Organização Mundial do Comércio tentem impor, aos países membros, políticas que subordinem a economia ao livre funcionamento dos mercados. Tudo isso, patrocinado e estimulado pelos Estados Unidos e demais grandes potências, que lideram politicamente o sistema mundial.

Uma das possibilidades abertas ao Brasil é procurar se inserir na economia mundial de acordo com as novas regras, que exigem crescente abertura do mercado interno às importações de mercadorias e de capitais e decrescente interferência estatal nos mercados internos, inclusive no de capitais e no de trabalho. Isso significa abrir mão das políticas clássicas de industrialização, que se mostraram indispensáveis a todos os países retardatários (inclusive os Estados Unidos) que, até o momento, foram capazes de penetrar no núcleo orgânico. Como por exemplo a preservação do mercado interno a setores de indústrias novas, chamadas de infantes; o favorecimento das mesmas em termos de financiamento, incentivos fiscais, compras públicas e assim por diante. 
Essa forma de inserção, que com toda justiça deve ser chamada de neoliberal, só deixa aberta uma via de desenvolvimento. A que resulta da inversão externa, sobretudo a que provém de empresas multinacionais (EMNs). E não há dúvida que estas investem em países periféricos, sobretudo no Brasil, que tem sido um dos maiores receptores de inversões externas diretas do Terceiro Mundo. Entre 1990 e 1998, a China recebeu US\$ 247 bilhões, vindo a seguir o Brasil e o México, com US\$ 69 bilhões, Singapura com US\$ 61, a Malásia com US\$ 38, a Argentina com US\$ 36, Indonésia com US\$ 26, Tailândia com US\$25, Coréia do Sul e Hungria com US\$ 20 e Hong Kong com US\$ 16 (Carta da SOBEET n.13)

Por esta enumeração, fica evidente que as EMNs investem sobretudo em países periféricos semidesenvolvidos. Elas o fazem para aproveitar as vantagens comparativas que eles oferecem, tais como mão-de-obra com alguma qualificação a baixo custo, imensos incentivos fiscais, acesso a mercados com potencial de crescimento. É duvidoso, para dizer o mínimo, que os investimentos das EMNs transfiram aos países periféricos nos quais investem funções nobres como planejamento estratégico, pesquisa tecnológica ou o desenvolvimento de novos produtos. Algumas EMNs estão globalizando seus grupos controladores, mas apenas entre países do núcleo orgânico (como a nova Daimler-Chrysler, por exemplo). Por isso, deve-se supor que a EMN típica mantém as funções mais nobres no país que abriga sua matriz, de modo que a inversão externa direta em país periférico, como o nosso, em nada contribui para que supere seu atraso.

A dependência em relação ao capital externo acarreta crescentes importações de mercadorias e capitais, inclusive sob a forma de empréstimos, pois as filiais das EMNs tendem a se abastecer e financiar no exterior. O resultado é a rápida deterioração das contas externas, seguida por fuga de capitais, ajustamento estrutural, em geral monitorado pelo FMI e, em seqüência por recessão que se prolonga até que as contas públicas e externas do país receptor se reequilibrem. O Brasil passou por esta experiência duas vezes nos últimos 18 anos. Apesar de abundantes inversões externas recebidas desde 1995, o nosso desenvolvimento tem sido medíocre.

A outra opção aberta ao Brasil de como se inserir na economia mundial é centrar o esforço de superação do atraso no mercado interno e suscitar o surgimento de EMNs brasileiras (ou sul-americanas), com competitividade suficiente para poder se defrontar com suas congêneres no mercado mundial. Esta opção implica desafiar a dominação financeira da economia mundial e o paradigma neoliberal imperante. $\mathrm{O}$ desenvolvimento seria fomentado mediante políticas de industrialização que aliam um setor público 
produtivo - energia elétrica, telecomunicações, saneamento básico, setores de alta tecnologia - a empresas controladas por residentes no país ou na região.

Essa forma de inserção deve ser chamada de intervencionista, pois entrega ao Estado o comando do processo de desenvolvimento, subordinando o funcionamento dos mercados às suas prioridades, não implicando isolamento da economia mundial, mas uma inserção na mesma que procura deliberadamente, para o Brasil, as vantagens usufruídas pelo núcleo orgânico. A inserção constitui a opção que possibilitou a superação do atraso pelo Japão e pela Coréia do Sul e que está permitindo tal superação à China nos dias atuais.

A inserção intervencionista não é uma volta ao passado, pois as políticas de desenvolvimento que funcionaram entre 1934 e 1980 dificilmente poderiam ser aplicadas de $2000 \mathrm{em}$ diante. O protecionismo, desta vez, teria de ser seletivo e combinado com planos de ganhos de competitividade que permitissem reduzir as barreiras gradualmente. As medidas de amparo fiscal e creditício teriam de ser negociadas em câmaras setoriais, com a participação de representantes dos consumidores e dos trabalhadores, para que os ganhos sejam repartidos democraticamente entre todos os participantes.

\section{O regime de desenvolvimento}

Este dilema se coloca diante da recente troca do regime de desenvolvimento, cujo comando foi sendo transferido do Estado ao mercado, ou melhor, ao capital financeiro. O BNDEs e a Petrobrás são remanescentes de um regime de desenvolvimento que está sendo deliberadamente destroçado por meio da privatização das maiores empresas estatais, inclusive da Vale do Rio Doce, e da maioria dos bancos estatais. Hoje, o desenvolvimento é liderado por EMNs em setores estratégicos, como finanças, telefonia e energia elétrica, monitorados passivamente pelo Banco Central e por novas Agências estatais, cuja missão é garantir que os contratos de concessão sejam cumpridos.

Uma das conseqüências da opção escolhida é a renúncia do governo federal a reduzir a desigualdade regional, que ainda é imensa no Brasil. Em vez de promover investimentos nas regiões mais atrasadas, ele tolera a guerra fiscal, da qual os únicos vencedores são as EMNs inversoras.

Outra conseqüência é a gradativa liqüidação da burguesia brasileira face à crescente dominação de setores industriais, comerciais e de serviços por multinacionais. Como a burguesia, tanto em 1994 como em 1998, apoiou 
por grande maioria o candidato que se responsabilizou pela mudança do regime de desenvolvimento, impõe-se a idéia de que a classe dominante brasileira auto-imolou-se, por convicção neoliberal ou por medo de que o poder pudesse cair nas mãos de um representante da classe trabalhadora.

$\mathrm{O}$ atual regime de desenvolvimento do Brasil, além de seu evidente fracasso em acelerar o desenvolvimento do país, consagrou o livre funcionamento dos mercados com sua propensão a concentrar renda e a ampliar desigualdade econômica. Como em outros países, também, ele suscita o desenvolvimento rápido da nova economia da informática e da telemática, gerando um número expressivo de postos de trabalho bem remunerados e que são ocupados por jovens, melhor adaptados às tecnologias de ponta. Ao mesmo tempo, ele libera pressões concorrenciais que expelem dos empregos grande número de assalariados, em todos os níveis, produzindo uma nova pobreza, que se traduz por níveis inéditos de desemprego, em termos de sua duração e de número de atingidos.

O regime neoliberal de desenvolvimento tem toda a probabilidade de continuar aprofundando a desigualdade econômica e social no Brasil, cujos índices são os maiores do mundo. O contraste entre riqueza recente de uns e miséria e exclusão recentes de outros produz diversas sociopatias, como a violência criminal cada vez maior nas metrópoles, corrupção em todos os níveis de governo, florescimento do consumo de produtos que causam dependência e da indústria ilegal que o abastece.

A alternativa ao regime neoliberal de desenvolvimento está sendo construída por governos municipais e estaduais, que implantam programas de bolsa-escola pelos quais os filhos dos pobres conseguem freqüentar a escola pública em lugar de trabalhar; outros desenvolvem orçamentos participativos, que permitem a representantes de diversas localidades e setores engajados discutir e negociar as prioridades de inversão dos recursos do orçamento público; e outros, ainda organizam desempregados em cooperativas de trabalho ou de produção, possibilitando sua reintegração à produção social em bases autogestionárias.

O regime alternativo de desenvolvimento toma por ponto de partida o enfrentamento da crise social. Ele tem como estratégia a mobilização das vítimas da crise a partir do Estado, em parceria com igrejas, sindicatos, ONGs e universidades. A Ação da Cidadania contra a Fome, de Betinho, que mobilizou milhões de pessoas em todo o país, pode ser considerada sua experiência primordial. A Ação não tem mais sua dimensão inicial, mas deixou frutos institucionais importantes, como a Rede de Incubadoras Tecnológicas de Cooperativas Populares, hoje já atuantes em 15 universidades espalhadas 
pelo Brasil e a Associação Nacional dos Trabalhadores de Empresas Autogeridas e de Participação Acionária - ANTEAG, que ajudou os trabalhadores de mais de 70 empresas em vias de falir ou falidas a transformá-las em empreendimentos por eles possuídos e administrados coletivamente.

Atualmente, essas organizações e mais o MST (criando cooperativas nos assentamentos), os Bancos do Povo municipais e estaduais (financiando microprodutores), os Clubes de Troca (utilizando moeda comunitária para criar mercado) estão lançando as bases de uma economia de mercado regida não pela busca do lucro mas pela geração de trabalho e renda, organizada solidariamente em mercados locais e regionais. Essas iniciativas são todas ainda muito recentes e poucas delas têm tido apoio efetivo de governos. Mas, os do Rio Grande do Sul e de Mato Grosso do Sul estão começando a mudar este panorama, ao lado de dezenas de prefeituras em todo o país.

O regime de desenvolvimento alternativo ao neoliberal só se viabilizará quando for assumido pelo governo federal. Quando isso acontecer, as prioridades serão outras. $\mathrm{O}$ crescimento da economia será condicionado pela demanda acrescida resultante de diversos programas nacionais de redistribuição de renda e geração de trabalho e renda, o que exigirá novamente políticas de industrialização, mas desta vez voltadas à satisfação de necessidades básicas de toda a população.

As políticas fiscal e monetária serão colocadas a serviço desses objetivos. A estabilidade dos preços será preservada, mas não mediante a restrição ao crescimento e a manutenção do desemprego. Ela terá de ser defendida contra pressões altistas numa economia (no dizer de Keynes) "em condições mais ou menos contínuas de pleno emprego". Isso exigirá a contratação coletiva de salários e preços, ao longo de cadeias produtivas, por representantes de empresários, trabalhadores e consumidores, servindo o governo de coordenador e árbitro do processo.

Este regime de desenvolvimento, que podemos chamar de solidário, poderá ser compatibilizado com certo grau de globalização da economia, desde que os setores estratégicos, como a intermediação financeira e os serviços de infra-estrutura estejam sob o controle de investidores, trabalhadores e usuários representando o conjunto do país. Multinacionais poderão continuar participando da economia, desde que aceitem a participação de trabalhadores e consumidores na tomada de certas decisões. O que não deve ser encarado como improvável se considerarmos o elevadíssimo volume de investimentos externos diretos na China, cuja economia tão pouco é dominada pelo capital financeiro. 
O regime solidário de desenvolvimento é um projeto que vai sendo formulado a partir de novas práticas sociais. As grandes experiências históricas de economia solidária sempre foram criadas como respostas a grandes desafios. No Brasil, não há de ser diferente. As novas práticas solidárias ainda estão dispersas e não são completamente conhecidas. Só agora começam a ser pesquisadas e sistematizadas, o que implica confessar que o projeto ainda não está maduro. Mas, face à imensidade da crise social, é provável que ele esteja pronto quando as condições políticas o tornarem o fulcro da esperança geral.

Paul Singer é professor da Faculdade de Economia e Administração da USP. 